\title{
Use of clinical simulation to improve diagnostic reasoning in nursing
}

\author{
Uso da simulação clínica para aprimorar o raciocínio diagnóstico na enfermagem \\ Uso de la simulación clínica para mejorar el razonamiento diagnóstico en enfermería
}

Ingrid Régia Lopes Jerônimo ${ }^{1}$ (1) Juliana Faria Campos ${ }^{1}$

Mauricio Abreu Pinto Peixoto ${ }^{1}$ Marcos Antônio Gomes Brandão ${ }^{1}$ (B)

1. Universidade Federal do Rio de Janeiro. Rio de Janeiro, RJ, Brasil.
Corresponding author:

Ingrid Régia Lopes Jerônimo.

E-mail: ingridregia@gmail.com

Submitted on $01 / 04 / 2018$

Accepted on 03/14/2018.

DOI: 10.1590/2177-9465-EAN-2017-0442

\section{Abstract}

Objectives: Propose a methodology for the construction of simulated scenarios and cases to improve diagnostic reasoning in nursing. Method: A methodological study was conducted using theories and concepts from the dual processing theory to develop cases and scenarios of clinical simulation for diagnostic reasoning in nursing through proper use of analytical and non-analytical reasoning. Results and discussion: This study presents and discusses issues of the theoretical framework and operational elements: structure of scenarios, preparation of simulation, briefing, debriefing, and modeling, incorporating any required content. The methodology articulates content that is compatible with analytical reasoning, non-analytical studies and diagnostic accuracy measurements of clinical validation studies. Conclusion: This study demonstrated the feasibility of modeling simulated cases that combine dual processing with diagnostic reasoning in nursing. Implications: Contribution to learning in a safer simulated environment, adopting theoretical bases from studies on human reasoning.

Keywords: Simulation; Nursing Diagnosis; Educational Technology; Methods; Learning.

\section{Resumo}

Objetivos: Propor uma metodologia de construção de cenários e casos simulados para aprimorar o raciocínio diagnóstico de enfermagem. Métodos: Estudo metodológico com bases teóricas e conceituais da Teoria do Duplo Processamento para construir casos e cenários de simulação clínica para o raciocínio diagnóstico de enfermagem pelo uso adequado dos raciocínios analítico e não analítico. Resultados e discussão: São apresentados e discutidos aspectos do referencial teórico e elementos operacionais, como: estrutura dos cenários, preparação da simulação, briefing, debriefing e modelagem, incorporando conteúdos necessários. A metodologia articula o conteúdo compatível com raciocínios analíticos, estudos não analíticos e medidas de acurácia diagnóstica de estudos de validação clínica. Conclusão: Entende-se ter demonstrado a exequibilidade da modelagem de casos simulados que integram o duplo processamento ao raciocínio diagnóstico de enfermagem. Implicações: Contribuição para o aprendizado em ambiente simulado mais seguro; adotando base teórica de estudos de raciocínio humano.

Palavras-chave: Simulação; Diagnóstico de Enfermagem; Tecnologia Educacional; Métodos; Aprendizagem.

\section{Resumen}

Objetivos: Proponer una metodología de construcción de escenarios y casos simulados para mejorar el razonamiento diagnóstico de enfermería. Métodos: Estudio metodológico con bases teóricas y metodológicas de la Teoría del Doble Proceso para construir casos y escenarios de simulación clínica para el razonamiento diagnóstico de enfermería utilizando correctamente los razonamientos analítico y no analítico. Resultados y discusión: Fueron presentados y discutidos aspectos del referencial teórico y elementos operativos: estructura de los escenarios, preparación de la simulación, briefing, debriefing y construcción, incorporando contenidos necesarios. La metodología articula contenido compatible con razonamientos analíticos, no analíticos y mediciones de precisión diagnóstica de estudios de validación clínica. Conclusión: Se entiende haber demostrado la factibilidad para construir casos simulados necesarios para el doble proceso del razonamiento diagnóstico de enfermería. Implicaciones: Contribución al aprendizaje en ambiente más seguro; adoptando base teórica de estudios de razonamiento humano.

Palabras clave: Simulación; Diagnóstico de Enfermería; Tecnología Educacional; Métodos; Aprendizaje. 


\section{INTRODUCTION}

Advances in nursing diagnosis studies have produced knowledge to better characterize the phenomena that affect people receiving health care. A worldwide tendency has pointed to broadening the understanding of diagnosis beyond medical practice, restructuring it to make it more linked to health problems, where other professionals in the field would have an active and collaborative participation. This change also allows advances for more precise diagnosis that involves at the same time the category, the health problem name, and the process to obtain it. ${ }^{1}$

However, even with this change of perspective and an interprofessional collaborative engagement in diagnostic decisions, there are still aspects that affect decisions, including: expansion of knowledge about diseases and human responses leading to a growing need to deal with more data; and the fact that most diseases and many human responses do not have necessary and sufficient diagnostic criteria for a diagnosis at the bedside. ${ }^{2}$

The two most widely used nursing diagnosis classification systems, the International Classification for Nursing Practice (ICNP) and NANDA International, have continuous revisions to incorporate new information about concepts and other elements of diagnosis. It has expanded and will continue to expand the amount of information requested from the diagnosticians. Even for those who do not use such classifications, the clinical knowledge of the area itself acts as the generator of new data and information that influence decisions on diagnoses and therapies.

It is logical to state that, as knowledge of signs and symptoms characterizing the diagnoses increases, consequently the challenge to produce a more accurate judgment based on these characteristics increases as well. In medicine, the absence of well-defined diagnostic criteria may lead to many combinations of signs and symptoms, creating obstacles to an accurate diagnosis. For example, a diagnosis that has 10 defining characteristics could, in theory, produce more than 600 combinations of signs and symptoms. ${ }^{3}$ The same would happen in nursing diagnoses in terms of combining signs and symptoms or risk factors.

Even so, the education process for diagnosis in nursing has used a similar model to that of medicine, that is, presenting a "diagnosis A", with a particular group of characteristics, and a "diagnosis B", with another group of characteristics, and so on. However, in real situations, characteristics or risk factors are rarely present altogether, with diagnoses that share common characteristics and create an obstacle to the process of diagnostic differentiation. ${ }^{2}$

With the complexity of diagnoses, diagnosticians tend to produce their own schemes of "more typical" simplified or optimized cases that - once they are learned - will be compared to a new diagnostic situation. Such mental shortcut strategies to simplify information are heuristic strategies. Heuristics have been studied in nursing at least since the 1980s-1990s acting as resources triggered by nurses when dealing with situations requiring complex decision making, placing them closer to optimized solutions, then assuming the "golden rule" standard and incorporating part of what is called intuitive decision or thinking of clinical nurses. Heuristics applied to diagnosis and decision making in nursing are cognitively economic, speeding up the reasoning process, and are widely used, especially by more experienced professionals in the form of intuitive reasoning. ${ }^{4}$ However, heuristics are also responsible for diagnostic errors and biases with undesirable consequences. ${ }^{5,6}$

Advances in research for clinical validation in diagnoses in nursing have brought information about better clinical criteria to diagnose, allowing such information to be used as the basis for the creation of analytical rules of diagnostic inclusion or rejection; for example, by using measurements of accuracy such as sensitivity, specificity, and predictive values. Studies have stated that nurses use probabilities and hypotheses of analytical thinking to make diagnoses and combine the use of heuristics of non-analytical thinking, justifying clinical validation studies; they also argue the links between the two types of thinking are essential for the development of reasoning models. ${ }^{5}$

Therefore, better diagnostic accuracy in nursing can be achieved by combining common non-analytical clinical reasoning and analytical reasoning that incorporates what has been produced in recent studies on clinical validation of nursing diagnoses. It can be explored in undergraduate and in-service training. Studies also confirm it by showing that, when making decisions, both types of reasoning are relevant, depending on the context and level of expertise. ${ }^{7}$

Clinical simulation, defined as a technique or a technology, aims to recreate the singularities of real-life situations, allowing students/professionals to acquire skills and competencies in a safe environment. ${ }^{8}$ It represents an effective strategy for the development of critical thinking and to increase the ability for assessment, reasoning and clinical decision, which are required in health care. The use of clinical simulation becomes a significant learning strategy where students who are not passive receptors participate in the construction of their knowledge, assuming a condition of coparticipants in the development of their expertise in the diagnostic reasoning in nursing.

Considering such need to gather resources from dual processing, the following question arises: How can we use clinical simulation to explore and develop analytical and non-analytical reasoning in nursing diagnosis?

This study aims to propose a methodology for the construction of simulated scenarios and cases to improve diagnostic reasoning in nursing. 
This study is organized into two topics. First, theories and concepts from dual processing in learning are described. Then, the aspects required to operationalize the methodological proposition are presented.

\section{THEORIES AND CONCEPTS FOR THE METHODOLOGY TO CONSTRUCT SIMULATED CASES}

Learning researchers have highlighted that dual processing theories are adequate references to understand the basic structures of knowledge and intellectual abilities, ${ }^{3}$ because they recognize the existence of analytical and non-analytical processes. Considering the evidence that diagnostic reasoning in nursing uses and should use both processes, it has become a logical selection to adopt a dual processing theory as the theoretical framework to guide the methodology construction. ${ }^{7,9}$

There are different dual processing theories available in the literature, with the general idea of two types of processing in common: a fast and intuitive process (type 1) and a slow and deliberative process (type 2). Since the two types of dual processing theories are very different, the proposition of clinical simulation was guided by the default-interventionist framework. ${ }^{9}$ Default-interventionist theories assume that type 1 processing generates intuitive default responses that will or will not be influenced by type 2 reflexive processing. ${ }^{9}$

Type 1 processing tends to be autonomous, with fast and associative aspects, requiring less effort of cognition, and discarding controlled attention, but these are not defining characteristics. ${ }^{9}$ Studies on clinical intuition of experienced nurses probably deal with type 1 processes that incorporate more advanced automatic associations, for example: quickly recognize the association between a new patient and an already analyzed/known prototype; develop implicit learning processes; and apply decision-making principles that operate at the level of automaticity. ${ }^{9,10}$

In the field of diagnostic studies, theoretically, type 1 processes would occur from a naturalistic decision-making approach that is related to the success of expert intuition, that is, the recognition of patterns stored in memory. The naturalistic decision recognizes that intuition is related to the recognition of clues or evidence that are part of tacit knowledge that is difficult to be articulated by the expert. ${ }^{10}$ In this perspective, the search for diagnostic expertise would have to involve expanding the repertoire of experiences, to increasingly develop a valid and timely clinical intuition.

Heuristics linked with type 1 processing would produce fast and frugal reasoning strategies that would place less value on the use of normative models to generate good judgments. In fact, it seems that as people gain experience and familiarity with situations, especially the complex ones, they tend to look for heuristics to create the "golden rule" that helps select a smaller number of data for a faster and simpler decision, requiring fewer efforts, but efficient. ${ }^{11}$ For example, the recognition-based heuristic typology occurs when the individual, in both known and unknown situations, infers that it is appropriate and considers known situations as those of the highest value of occurrence. On the other hand, recognition would not be possible when the two situations are unknown. Therefore, reason-based heuristics are applied by selecting the best clue and ignoring the others. In health, matching heuristic is also commonly used, in which a small subgroup of clues is collected, and the prediction is based on value of a single clue. ${ }^{11,12}$

However, heuristics also disturb professional judgment, which has been verified in studies on heuristics and tendencies. Studies show that, when individuals are asked to judge, they tend to act inconsistently, getting to different conclusions based on the same information of a specific case, if it happens on different occasions. In clinical judgment, another undesirable phenomenon usually happens, which is called illusion of validity, that is, an unjustified tendency to keep considering an impression as valid, despite evidence to the contrary. ${ }^{10}$

Type 2 processing, however, correlates with slow, sequential elements and linked with intelligence in general, enabling hypothetical thinking, mental simulations, and consequential decision making. In this type of processing, the working memory is also required to discard influences from representations of imaginary situations. Its functional characteristics would be based on rules, of general, abstract, logical, and egalitarian domain, not based on stereotypes. ${ }^{9}$

In the field of diagnosis, the types of algorithmic and hypothetical-deductive reasoning work in processes related to type 2 processing, as well as prescriptive decision-making models. ${ }^{9}$ Algorithmic reasoning is based on contributions derived from statistical theories and decision-making theories, where the Bayesian theorem and decision analysis show the importance of subjective interpretation of probabilities. In the Bayesian perspective, decisions consider hypotheses that are characterized by a subjective probability, that is, how much one assumes that hypothesis is true. The use of hypotheticaldeductive reasoning was investigated in studies on nursing in the 1980s showing nurses make judgments about the situation of patients in a rational process, generating one or more hypotheses that are tested along the deductive process. ${ }^{11}$

Prescriptive decision-making models are associated with measurements of accuracy, sensitivity, specificity, predictive values, prevalence, likelihood ratios, and precision. Such measurements would support a diagnostic decision in nursing based on how appropriate is a result of a clinical test or indicator 
of the sign or symptom type to conclude by the presence or absence of the diagnosis. The principle is premised on the Bayesian probability estimates whereby the presenting signs and symptoms can predict a corresponding diagnosis (dependent variable). ${ }^{11}$

Dual processing theories are important for diagnostic reasoning in nursing, because diagnoses represent a category of phenomena that have a poorly defined nature, allowing the two processing systems to act concomitantly. ${ }^{3,7}$ Indeed, nursing diagnoses have aspects that define them as poorly-defined phenomena/concepts, as follows: have few reference standards; need defining characteristics that would be the diagnostic criteria; and be linked with different concepts that are not synonyms, but are often used by some as if they were, such as human response, problem, need, among others.

When we think of those hundreds of nursing diagnoses that are categorized and continually added to the taxonomies of the ICNP and NANDA International and relate it to the reach of nursing practice and heterogeneities of education in nursing, we have a discouraging picture for teaching and the use of strategies exclusively based on heuristics, not to mention the problems of bias and diagnostic errors due to the use of heuristics already found in Medicine. ${ }^{2}$ On the other hand, the dynamic character of nursing practice and its marked familiarity with the comprehensive dimensions of human beings makes exclusive analytical thinking not productive in situations that require fast and accurate assessments and decisions. Therefore, dual processing is preferred.

\section{ASPECTS FOR THE OPERATIONALIZATION OF THE PROPOSED METHODOLOGY FOR SIMULATED CASES}

After selecting the dual processing reference, the authors of this study defined the phases and parameters for the development of a teaching methodology aligned with the real activity that should be simulated. For this purpose, aspects related to general and specific planning, scenario development and debriefing are addressed. The description also presents elements of procedure guides and study guides. ${ }^{13}$

In the planning phase, the starting point is the definition of a general objective to be achieved with the new methodology, that is: develop the nursing diagnosis based on the dual processing cognitive system. To achieve the objective, and considering that type 1 processing system uses prototype cases and exemplary cases, this study chose to use a methodological proposal that works with clinical cases in simulated scenarios. A simulated scenario refers to the report of a clinical situation that allows the development of specific learning objectives, but which mandatorily requires the participation and interaction of participants with the didactic strategy, different from clinical cases, which can be used statically. ${ }^{14}$

When planning simulated scenarios, one can choose to use low-, medium- or high-fidelity simulators, simulated patients, patients in realistic virtual environments, and role-playing. ${ }^{15} \mathrm{All}$ these options for the operationalization of scenarios should allow dual processing characteristics to be processed, provided the case structure and incorporated content take into account the strategies commonly adopted in type 1 and type 2 processes.

The selection of strategy and technique to be used can be influenced by specific objectives and different interests, but of high relevance, when compared to the diagnostic decision. Specific learning objectives and the scenario complexity influence the simulator selection. For example, when using simulated patients, actors or role-playing could facilitate awareness and improve self-confidence in a (non-technical) behavioral scenario. ${ }^{16} \mathrm{It}$ should be noted that highly technological simulators are not always the most suitable option for more complex scenarios. The task of developing procedure guides for the scenarios is for the enablers of learning, who can refer to the literature. ${ }^{13}$

Once the objectives and techniques have been defined, the construction of the cases that will incorporate the essential elements into the diagnosis will be conducted. In this step, the following is recommended: define whether the case will have a central diagnosis or multiple diagnoses; define a context or specialty; select additional elements related to diagnoses in the physical, environmental, social, cultural and institutional dimensions; define outcome criteria and results for the case. Constructed cases may also be more or less directed to preserving realistic and recent elements of health care to everyone involved, and preserving simplicity, objectivity and comprehensiveness. ${ }^{17}$

The cases should have content that allows the nursing diagnostic reasoning guided by types 1 and 2 cognitive systems considering the value of their relations. ${ }^{6}$ Therefore, the cases should contain information that encourages the use of heuristics common to dynamic decision environments, such as pattern recognition and matching heuristic. ${ }^{18}$ Particularly the most expert professionals are likely to seek in the cases elements that are compatible with their contexts of action that enable the use of a particular type of pattern recognition called recognitionprimed decision. ${ }^{10}$ On the other hand, the incorporation of information from accuracy measurements derived from clinical validation studies offers the individual the possibility of using this knowledge as a supporter of type 2 reasoning model.

To facilitate the case development, the specialized languages of ICNP or NANDA International can be used, including the selection of standardized terms, depending on the 
objectives and characteristics of the teaching-learning process of reasoning. A system of data documentation and organization is also important in the case production, as well as the use of problem-oriented, domain-oriented models, guided by diagnostic hypotheses, among others. Particularly for analytical reasoning, current literature and consistent evidence are recommended to incorporate it into the case content. Clinical validation studies of nursing diagnoses are the first choices for this purpose as they offer measurements of diagnostic tests of clinical indicators or defining characteristics for accurate decisions. ${ }^{19}$

For the clinical case development, additional aspects inherent to this type of context are also incorporated, including selection of the care unit involved, selection of equipment and devices to be used, preparation of simulator/simulated patient/ environment, and aspects for briefing and debriefing. ${ }^{17}$ Expert nurses tend to recognize a more comprehensive set of data not always consciously, and then they develop a more suitable model for data interpretation. Considering this fact, the cases should incorporate a broader view of the context and become data rich as the diagnostician's expertise is greater.

In relation to the simulator fidelity, in order to reach the objective of this methodology, it should involve simulated scenarios of high fidelity and complexity, where the high degree of environmental, simulator/patient and psychological fidelity enable the clinical and critical reasoning for the resolution of daily complex situations of clinical practice. ${ }^{20}$ Physical fidelity refers to the environment and simulator and affects the degree of sensory similarity between the simulated and the real environments. However, the psychological fidelity influences the participant's perception of the simulated environment, affecting the way he performs his actions. ${ }^{21}$

High-fidelity environment and the use of simulators for this type of scenario should prioritize and focus the clinical history created. For example, a scenario that addresses the topic of weaning from ventilation using the nursing diagnosis of dysfunctional ventilatory weaning response should occur in an intensive care unit, preserving its physical aspects such as hemodynamic and ventilation monitoring, catheters, orotracheal tube, infusion pumps with medications and specific solutions and mechanical ventilation, to ensure the target public recognizes the environment. In addition, having laboratory and imaging exams for reference during the scenario. Actors playing the role of family members or information about them may also be available. The simulator or simulated patient should be prepared to interact with the student/professional answering their questions and presenting the signs and symptoms selected for the case.

The case summary should also be clearly presented to the participants, for example: "You will evaluate a patient who is in weaning from ventilation." So that this construct shows adherence to the proposed pedagogical objectives, for example: accurately develop the diagnostic reasoning of the dysfunctional ventilatory weaning response. This strategy allows the participant's role to be focused on specific objectives ensuring satisfactory execution and resolution of the scenario.

Also about the example, the patient's history data and situation should be described, such as: age, clinical condition and evolution that led to hospitalization and use of mechanical ventilation, vital data before the connection with ventilation prosthesis and procedures to which the patients were submitted, that is, the context that generated the scenario to be explored, which can be selected from a real case scenario. All these elements should be compatible with the models of data documentation and organization to be defined still in the planning phase, to ensure a learning experience that is consistent with the practice or training of students/professionals.

After considering the general planning already presented, and after taking a single nursing diagnosis of interest as the starting point, one or more studies should be selected that present measurements of sensitivity, specificity, false positive and false negative rates for each sign, symptom or defining characteristic of the diagnosis. For risk diagnosis, odds ratio or relative risk should be used.

For accuracy measurements, clinical indicators greater than $50 \%$ sensitivity and specificity, and $20 \%$ or more for false positive and false negative rates are recommended, depending on whether the scenario is to promote the diagnosis acceptance or rejection, or even if it is for a scenario that induces judgment failures like false positive or negative type. For risk factors, consider odds ratio values greater than 1.0 in the minimum value for the confidence interval. The amount of evidence will depend on the extent of the case and the clinical coherence of evidence insertion, since the diagnostic accuracy is not totally dependent on the number of clinical indicators. For some nursing diagnoses, one characteristic that defines it is sufficient, but others require at least three to four or even six for an accurate judgment. ${ }^{22}$

When seeking to make the reasoning model more complex or deepen the discussion in debriefing, other measurements can be incorporated when selecting the defining characteristics, such as: likelihood ratio, predictive values, and accuracy or efficiency, ${ }^{19}$ which requires conceptual knowledge of what each statistical information represents in clinical validation studies, but the benefits can be significant and contribute to the production of more adequate cases and simulations to the development of reasoning that is compatible with dual processing.

After defining the clinical indicators (signs and symptoms, defining characteristics or risk factors), then the scenarios will be modeled according to the type of diagnosis that guided the case construction. For problem-focused diagnoses, four scenarios 
should be constructed that incorporate defining characteristics with greater sensitivity, specificity and false positive and false negative rates into the content of the cases.

Figure 1 shows how the scenarios should be organized.

Figure 1. Organization of simulation scenarios according to diagnostic decisions. Source: created by the authors, 2017.

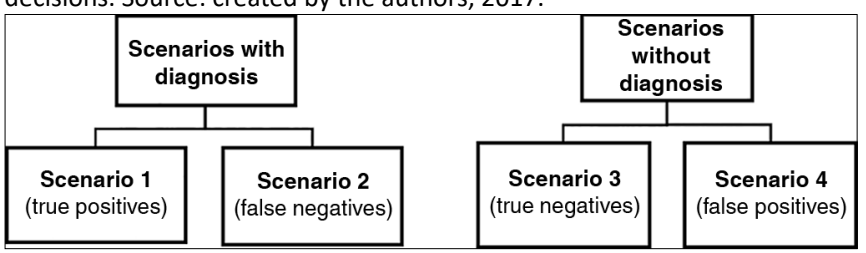

For problem-focused diagnoses, the scenarios should have present or absent diagnostic outcomes in agreement or disagreement with the evidence from clinical validation studies. In an ideal model, scenarios 1 and 3 would tend to allow the pattern recognition reasoning that were based on scientific evidence. Scenarios 2 and 4 should be recognized as incongruent since the clues present in the cases would point to a different diagnosis. However, in cases of risk diagnosis, the thinking is similar, only changing the measurements and the absence of a fourth scenario.

In congruent scenarios (1 and 3), sensitive and specific clinical indicators should be incorporated, as follows: scenario 1 should have high sensitivity indicators, and additionally, high specificity indicators for diagnostic confirmation; and scenario 3 there should have an explicit mention of the absence of high specificity indicators.

In incongruent scenarios 2 and 4, indicators with high rates of incorrect classifications should be included. Scenario 2 should have the highest false negative rates and scenario 4 , the false positive rates.

For risk diagnoses, at least two scenarios should be constructed: one with risk factors compatible with the diagnosis; therefore, with odds ratio that meets the minimum criteria, and another scenario that is compatible with the diagnosis rejection, without risk factors. Optionally, another scenario can be constructed with risk factors of odds ratio less than or equal to 1.0 to encourage biased judgments of non-existent risk.

During the execution of scenarios, which should last up to 15 minutes, audiovisual resources for filming may be used to record it for subsequent debriefing. The instructor should be aware of the critical actions of the scenario participant, which indicate that the objectives have been achieved and the scenario can be ended. ${ }^{23}$
Debriefing is an intentional process performed after the scenario execution, providing the active learning by technical, affective, cognitive and psychosocial skills assessed for scenario development. During the debriefing session of around 30 minutes, the instructor and the participant re-examine the situation and the facilitator encourages the participant to think of his actions and express such thinking for a group analysis. ${ }^{17}$

When proposing this methodology for the development of diagnostic reasoning, at the time of debriefing, the participant should express whether the nursing diagnosis was present or absent and indicate what evidence/data he used to make the diagnostic decision. From the perspective of nursing diagnostic reasoning, the debriefing would represent a unique opportunity to explore the influences of the type of processing used by the student/professional.

Metacognition, with its monitoring and cognitive control properties, can help debriefing by allowing awareness of the reasoning process. Metacognition represents a higher order thinking process that, together with the development of cognition, is considered essential for clinical reasoning. ${ }^{24}$ During the debriefing session, the procedures to encourage self-questioning would tend to show the occurrence of metacognitive experiences related to judgment about what is known or not to the individual. Strategies and instruments that encourage the recall of metacognitive experiences and expand the metacognitive knowledge are available in the literature and can be applied..$^{25}$ Such strategies and instruments would operate as guides for clinical simulation studies, as they fulfill their primary function of developing clinical reasoning and knowledge application, extrapolating more technical dimensions of handling guides and procedures guides. ${ }^{13}$

A deeper thinking in the use of metacognitive strategies may require time to be extended from usual 30 minutes and should be a carefully considered need, considering the cost-benefit ratio for learning.

Table 1 shows the steps required for the operationalization of proposed methodology.

\section{FINAL CONSIDERATIONS}

This study presented theoretical, conceptual and operational aspects of using clinical simulation as a methodology for the clinical teaching of nursing diagnosis, proposed as a new educational technology for the implementation of the nursing process, using a dual processing theory. Through the proposed methodology, the theoretical bases that guide and support the elements incorporated in the methodological description were indicated. 
Table 1. Summary - operationalization of proposed methodology

\begin{tabular}{|c|c|}
\hline \multicolumn{2}{|c|}{ OPERATIONALIZATION OF PROPOSED METHODOLOGY } \\
\hline General planning & Purpose, action or recommendation \\
\hline $\begin{array}{l}\text { Define the general objective to be achieved in the si- } \\
\text { mulation }\end{array}$ & $\begin{array}{l}\text { Acquisition of skills and competencies for the nursing diagnostic } \\
\text { reasoning guided by the dual processing cognitive system. }\end{array}$ \\
\hline Select a learning strategy & Clinical case in a simulated scenario is recommended. \\
\hline Select the simulator fidelity & $\begin{array}{l}\text { The following is recommended: low-, medium- and high-fidelity } \\
\text { simulators, simulated patients (actors), simulation in virtual } \\
\text { environments or role-playing. }\end{array}$ \\
\hline Define specific objectives & $\begin{array}{l}\text { Expansion of skills, correction of biases/tendencies of judgment, } \\
\text { development of level of expertise, among others. }\end{array}$ \\
\hline Plan the construction of cases & $\begin{array}{l}\text { Actions: select the central diagnosis of the case, the context or } \\
\text { specialty, additional content, and content related to the diagnoses } \\
\text { and outcome criteria and results. Use: classification of nursing } \\
\text { diagnoses, data documentation and organization system, and } \\
\text { current literature with consistent evidence. }\end{array}$ \\
\hline $\begin{array}{l}\text { Define additional aspects of the case at the moment } \\
\text { of simulation }\end{array}$ & $\begin{array}{l}\text { Actions: define the care unit involved, the equipment and } \\
\text { devices to be used. Foresee preparation of simulator/simulated } \\
\text { patient/environment. }\end{array}$ \\
\hline Specific planning & Decision or information required \\
\hline $\begin{array}{l}\text { Select the measurements of sensitivity, specificity, false } \\
\text { positive and negative rates of the central diagnosis of } \\
\text { the case. For risk diagnosis, odds ratio or relative risk } \\
\text { should be used. }\end{array}$ & $\begin{array}{l}\text { Actions: select the highest values, including the confidence } \\
\text { intervals of the measurements. For sensitivity and specificity, use } \\
\text { values greater than } 50 \% \text {, and for false positive and negative rates, } \\
\text { values greater than } 20 \% \text {. }\end{array}$ \\
\hline $\begin{array}{l}\text { Model } 4 \text { scenarios for real diagnoses, and } 2 \text { to } 3 \\
\text { scenarios for risk diagnoses. }\end{array}$ & $\begin{array}{l}\text { Actions: incorporate accurate and non-accurate indicators to the } \\
\text { logical case and clinically articulated to the other case content. Try } \\
\text { to construct a case that is close to patterns of clinical reality expe- } \\
\text { rienced by the apprentices participating in the simulation. }\end{array}$ \\
\hline Development of simulated scenario & Decision or information required \\
\hline Control scenario duration & The scenarios should last up to 15 minutes. \\
\hline Manage audiovisual resources & $\begin{array}{l}\text { Actions: use audiovisual resources for filming, when available. Use } \\
\text { the recorded material for subsequent debriefing. }\end{array}$ \\
\hline Observe critical actions & $\begin{array}{l}\text { The instructor should pay attention to the critical actions of } \\
\text { the participant in the scenario, indicate objectives have been } \\
\text { achieved and the scenario can be ended. }\end{array}$ \\
\hline Debriefing & Decision or information required \\
\hline Conduct debriefing & $\begin{array}{l}\text { Debriefing should always be guided by previously set learning } \\
\text { objectives. The participant should express whether the nursing } \\
\text { diagnosis was present or absent and which evidence/data allowed } \\
\text { him to make such diagnostic decision. A 30-minute period may be } \\
\text { required for this activity. }\end{array}$ \\
\hline
\end{tabular}


Dual processing theories seem to be useful as references for the construction of proposed methods and technologies that use simulated cases for nursing diagnosis. A combination of type 1 and type 2 processing can be operationalized in simulations, and the pedagogical planning of case simulations can benefit from the tendency of nurses to use heuristics and from the application of analytical procedures.

The proposed methodology of simulated cases based on a dual processing theory of the default-interventionist structure uses results from nursing diagnostic validation studies in the composition of simulated cases; then, it may help incorporate such information in undergraduate or in-service training narrowing the margins between theory-practice and serviceacademia.

Therefore, the structuring of the proposed methodology uses the two cognitive systems as complementing one another, promoting nursing diagnosis learning in a simulated environment, which is more reliable and favorable for the construction of critical and accurate clinical reasoning.

\section{ACKNOWLEDGMENTS}

To the Higher School of Nursing of Coimbra (ESEnfC), Portugal, for the partnership that resulted in the production of the materials that grounded the development of this study.

\section{REFERENCES}

1. Considine J. Nurses, diagnosis and diagnostic error. Diagnosis (Berl) [Internet]. 2017 Nov; 4(4):197-9. Available from: https://www.ncbi.nlm. nih.gov/pubmed/29536936

2. Papa FJ. Learning sciences principles that can inform the construction of new approaches to diagnostic training. Diagnosis (Berl) [Internet]. 2014 Jan; 1(1):125-9. Available from: http://www.degruyter.com/view/j/ dx.2014.1.issue-1/dx-2013-0013/dx-2013-0013.xml

3. Papa FJ, Li F. Evidence of the preferential use of disease prototypes over case exemplars among early year one medical students prior to and following diagnostic training. Diagnosis (Berl) [Internet]. 2015 Dec; 2(4):217-25. Available from: http://www.degruyter.com/view/j/ dx.2015.2.issue-4/dx-2015-0024/dx-2015-0024.xml

4. Kuiper R, Pesut D, Kautz D. Promoting the Self-Regulation of Clinical Reasoning Skills in Nursing Students. Open Nurs J [Internet]. 2009 Oct; 3:76-85. Available from: http://benthamopen.com/ABSTRACT/ TONURSJ-3-76

5. O'Neill ES. Heuristics reasoning in diagnostic judgment. J Prof Nurs [Internet]. 1995 Jul/Aug; 11(4):239-45. Available from: http://linkinghub. elsevier.com/retrieve/pii/S8755722395800263

6. Dowding D, Gurbutt R, Murphy M, Lascelles M, Pearman A, Summers B. Conceptualising decision making in nursing education. J Res Nurs [Internet]. 2012 Jul; 17(4):348-60. Available from: http://journals. sagepub.com/doi/10.1177/1744987112449963

7. Evans JSBT. Dual-Processing Accounts of Reasoning, Judgment, and Social Cognition. Annu Rev Psychol [Internet]. 2008 Jan; 59:255-78. Available from: http://www.annualreviews.org/doi/10.1146/annurev. psych.59.103006.093629
8. Kim J, Park JH, Shin S. Effectiveness of simulation-based nursing education depending on fidelity: a meta-analysis. BMC Med Educ [Internet]. 2016 May; 16:152. Available from: http://bmcmededuc. biomedcentral.com/articles/10.1186/s12909-016-0672-7

9. Evans JSBT, Stanovich KE. Dual-Process Theories of Higher Cognition. Perspect Psychol Sci [Internet]. 2013 May 7; 8(3):223-41. Available from: http://journals.sagepub.com/doi/10.1177/1745691612460685

10. Kahneman D, Klein G. Conditions for intuitive expertise: a failure to disagree. Am Psychol [Internet]. 2009 Sep; 64(6):515-26. Available from: https://www.ncbi.nlm.nih.gov/pubmed/?term=Kahneman+ D.+Conditions+for+Intuitive+Expertise.+2009\%3B64(6)\%3A515 $\%$ E2\%80\%9326

11. Rashotte J, Carnevale FA. Medical and nursing clinical decision making a comparative epistemological analysis. Nurs Philos [Internet]. 2004 Jul; 5(2):160-74. Available from: https://www.ncbi.nlm.nih.gov/pubme $\mathrm{d} /$ ?term=Medical+and+nursing+clinical+decision+making\%3A+a+co mparative+epistemological+analysis.+Nurs+Philos.+2004+Jul\%3B5( 2)\%3A160\%E2\%80\%9374.

12. Thompson C, Dowding D. Essential Decision Making and Clinical Judgement for Nurses. 1st ed. New York: Elsevier Health Sciences; 2009. $288 p$

13. Amaya Afanador A. Importancia y utilidad de las "Guías de simulación clínica" en los procesos de aprendizaje en medicina y ciencias de la salud. Univ Médica [Internet]. 2011 Jul/Sep; 52(3):309-14. Available from: http://www.redalyc.org/articulo.oa?id=231022506006

14. Alinier G. Developing High-Fidelity Health Care Simulation Scenarios: A Guide for Educators and Professionals. Simul Gaming [Internet] 2011 Feb 14; 42(1):9-26. Available from: http://journals.sagepub.com/ doi/10.1177/1046878109355683

15. Nehring WM, Lashley FR. Nursing Simulation: A Review of the Past 40 Years. Simul Gaming [Internet]. 2009 Jul; 40(4):528-52. Available from: http://journals.sagepub.com/doi/abs/10.1177/1046878109332282

16. Negri EC, Mazzo A, Martins JCA, Pereira Junior GA, Almeida RGS Pedersoli CE. Clinical simulation with dramatization: gains perceived by students and health professionals. Rev Latino Am Enferm [Internet] 2017 Aug; 25:e2916. Available from: http://www.scielo.br/scielo. php?script=sci_arttext\&pid=S0104-11692017000100604\&Ing=en\&t $\mathrm{ng}=\mathrm{en}$

17. Fabri RP, Mazzo A, Martins JCA, Fonseca AS, Pedersoli CE, Miranda FBG, et al. Development of a theoretical-practical script for clinical simulation. Rev Esc Enferm USP [Internet]. 2017 Apr; 51:e03218. Available from: http://www.scielo.br/scielo.php?script=sci_ arttext\&pid=S0080-62342017000100418\&lng=en\&tIng=en

18. Banning M. A review of clinical decision making: models and current research. J Clin Nurs [Internet]. 2008 Jan; 17(2):187-95. Available from: http://doi.wiley.com/10.1111/j.1365-2702.2006.01791.x

19. Lopes MVO, Silva VM, Araujo TL. Methods for Establishing the Accuracy of Clinical Indicators in Predicting Nursing Diagnoses. Int $\mathrm{J}$ Nurs Knowl [Internet]. 2012 Oct; 23(3):134-9. Available from: http://doi. wiley.com/10.1111/j.2047-3095.2012.01213.x

20. Grady JL, Kehrer RG, Trusty CE, Entin EB, Entin EE, Brunye TT. Learning nursing procedures: the influence of simulator fidelity and student gender on teaching effectiveness. J Nurs Educ [Internet]. 2008 Sep; 47(9):403-8. Available from: https://www.ncbi.nlm.nih.gov/pubme $\mathrm{d} /$ ?term=earning+nursing+procedures $\% 3 \mathrm{~A}+$ the+influence+of+simula tor+fidelity+and+student+gender+on+teaching+effectiveness.+J+Nu rs+Educ.+2008+Sep\%3B47(9)\%3A403\%E2\%80\%938

21. Maran NJ, Glavin RJ. Low- to high-fidelity simulation - a continuum of medical education? Med Educ [Internet]. 2003 Nov; 37(Suppl 1):228. Available from: https://www.ncbi.nlm.nih.gov/pubmed/?term=Low+to+high-fidelity+simulation+-+a+continuum+of+medical+ed ucation $\% 3 \mathrm{~F}+$ Med+Educ. $+2003+$ Nov\%3B37+Suppl+1\%3A22 $\%$ E2\%80\%938 
22. Brandão MAG, Cerqueira FA, Matos LN, Campos JF, Peixoto MAP, Primo CC. Características definidoras da Resposta Disfuncional ao Desmame Ventilatório como indicadores de acurácia do desmame ventilatório. Rev Bras Enferm [Internet]. 2014 Oct; 67(5):737-43. Available from: http://www.scielo.br/scielo.php?script=sci_arttext\&pid=S003471672014000500737\&lng=pt\&tlng=pt

23. Waxman KT. The development of evidence-based clinical simulation scenarios: guidelines for nurse educators. J Nurs Educ [Internet]. 2010 Jan; 49(1):29-35. Available from: https://www.ncbi.nlm.nih.gov/pubme $\mathrm{d} /$ ?term=Waxman+KT.+The+Development+of+Evidence-Based+Clini cal+Simulation+Scenarios\%3A+Guidelines+for+Nurse+Educators.+J +Nurs+Educ.+2010+Jan\%3B49(1)\%3A29\%E2\%80\%9335
24. Banning M. Clinical reasoning and its application to nursing: Concepts and research studies. Nurse Educ Pract [Internet]. 2008 May 8(3):177-83. Available from: http://linkinghub.elsevier.com/retrieve/pii/ S1471595307000595

25. Chartier L. Use of Metacognition in Developing Diagnostic Reasoning Skills of Novice Nurses. Int J Nurs Terminol Classif [Internet]. 2001 Apr; 12(2):55-60. Available from: http://doi.wiley.com/10.1111/j.1744618X.2001.tb00119.x 